\title{
Redes sociais de produção e colaboração tecnológica para o descarte de resíduos de equipamentos elétricos e eletrônicos ${ }^{1}$
}

\author{
Luciara Cid Gigante, Camila Carneiro Dias Rigolin, Júlia Fernandes Marcelo
}

\begin{abstract}
Resumo
Introdução: Esta pesquisa teve como objetivo geral mapear e analisar as redes sociais de produção e colaboração tecnológica, em documentos de patentes, relativas às inovações sobre descarte de lixo tecnológico, também chamado de Resíduos de Equipamentos Elétricos e Eletrônicos. 0 referencial teórico é pertinente ao campo de estudos "Ciência, Tecnologia e Sociedade". Método: A metodologia baseou-se na aplicação das técnicas relativas à Análise de Redes Sociais, caracterizada pelo mapeamento e mensuração dos fluxos e relações e colaborações entre os inventores das patentes de inovações relativas ao descarte de lixo tecnológico. Resultados: Os resultados apontam a pouca expressividade da colaboração internacional neste domínio, e a liderança da China no que diz respeito ao registro de patentes sobre descarte de Resíduos de Equipamentos Elétricos e Eletrônicos. Conclusões: As possíveis causas da pouca colaboração internacional nesta área de pesquisas tecnológicas derivam da ausência de harmonização legal no campo da propriedade industrial, associada às distâncias geográficas, barreiras linguísticas e altos custos incorridos na colaboração tecnológica transnacional.
\end{abstract}

\section{Palavras-chave}

Lixo tecnológico. Colaboração em redes sociais. Patentes. Pesquisas tecnológicas. Produção tecnológica. Inovação tecnológica.

\section{Introdução}

O problema do crescente volume de resíduos sólidos gerados por bilhões de consumidores tem sido apontado como um dos mais graves da atualidade. A escassez de áreas para a implantação de novos aterros para a disposição de resíduos, aliada às limitações existentes para a recuperação dos materiais não renováveis, o baixo grau de implantação de novas alternativas de tratamento e reciclagem representam, hoje, um desafio.

Segundo Ferreira e Ferreira (2008), os danos causados ao meio ambiente demostramse irreversíveis, seja por conta da criação de lixões com milhares de aparelhos eletrônicos (computadores, televisores, telefones celulares) descartados com uma velocidade cada vez maior, seja na forma de doenças causadas pelo manejo e os riscos causados pelas substâncias tóxicas presentes em tais equipamentos.

A construção de possíveis soluções para o descarte de resíduos sólidos é uma temática multidimensional, que levanta questões referentes: à produção de inovação e à geração de artefatos tecnológicos; à lógica concorrencial da indústria de equipamentos eletrônicos, em que a obsolescência programada é parte das "regras do jogo"; à dimensão social e cultural das práticas de consumo na sociedade contemporânea; aos impactos ambientais e à formulação de políticas públicas nas esferas federal, estadual e local. Portanto, demanda o debate ampliado entre diversos atores sociais - universidades e institutos de pesquisa, gestores de políticas (policy makers), empresas privadas e cidadãos de forma geral. Os danos ao meio ambiente aliados à perda de

\footnotetext{
${ }^{1}$ Os resultados deste artigo foram apresentados oralmente no $3^{\circ}$ Encontro Brasileiro de Bibliometria e Cientometria, ocorrido em agosto de 2012, na cidade de Gramado-RS.
} 
dinheiro, proveniente da má utilização desse lixo, justificam a movimentação de toda a sociedade para a solução desse problema.

A geração dos resíduos urbanos pode ser explicada pelo sistema de produção flexível, que permitiu uma aceleração do ritmo da inovação do produto ao lado da exploração de nichos de mercado altamente especializados e de pequena escala (HARVEY, 1993). Para o autor, o tempo de giro foi reduzido pelo uso de novas tecnologias (automação, robôs) e de novas formas organizacionais, tais como o sistema de gerenciamento de estoques "just-in-time", que corta drasticamente a quantidade de material necessária para manter a produção fluindo.

Harvey (1993, p. 148) ressalta que "a aceleração do tempo de giro na produção teria sido inútil sem a redução do tempo de giro no consumo". A meia vida de um produto fordista típico era de cinco a sete anos, mas a acumulação flexível diminuiu este tempo em mais da metade em setores como o têxtil, enquanto que em outros, como o de tecnologias de informação, a meia vida tem caído para menos de dezoito meses. Para o autor,

\footnotetext{
[a] acumulação flexível foi acompanhada na ponta do consumo, portanto, por uma atenção muito maior às modas fugazes e pela mobilização de todos os artifícios de indução de necessidades e de transformação cultural que isso implica. A estética relativamente estável do modernismo fordista cedeu lugar a todo o fermento, instabilidade e qualidades fugidias de uma estética pós-moderna que celebra a diferença, a efemeridade, o espetáculo, a moda e a mercadificação de formas culturais. (HARVEY, 1993, p. 148)
}

Bauman (2007) e Costa (2004) discutem a questão da sociedade de consumo baseada na premissa da satisfação dos desejos humanos, de uma forma que nenhuma sociedade do passado pôde realizar ou sonhar. A promessa de satisfação, no entanto "só permanecerá sedutora enquanto o desejo continuar irrealizado; o que é mais importante, enquanto houver uma suspeita de que o desejo não foi plena e totalmente satisfeito" (BAUMAN, 2007, p. 106).

O corolário da premissa anterior é a completa autonomia do indivíduo em suas escolhas. Sua preferência é irredutível a qualquer instância ou esfera explicativa que não seja o que ele efetivamente fez por meio de suas escolhas (ABRAMOVAY, 2004). Neste caso, o ator econômico não se comporta como autômato, que reage a estímulos do mercado, mas de acordo com elementos subjetivos, que não são individuais, mas sociais (RAUD-MATTEDI, 2005). O comportamento é também justificado pela tradição, pelo direito, pela moral e os interesses são socialmente construídos.

Porém, é necessário ressaltar que, além do progresso e bem-estar, a ciência e a tecnologia igualmente podem implicar em danos (à saúde e ao meio ambiente, por exemplo) e controvérsias éticas e morais. É a chamada sociedade de risco a que o sociólogo Ulrich Beck designa como "uma fase no desenvolvimento da sociedade moderna, em que os riscos sociais, políticos, econômicos e individuais tendem cada vez mais a escapar das instituições para o controle e a proteção da sociedade industrial" (BECK, 1997, p. 15).

A sociedade de risco é caracterizada por Beck (1997, p. 15) em duas fases: a primeira é "um estágio em que os efeitos e as auto-ameaças (sic) são sistematicamente produzidos, mas não se tornam questões públicas ou o centro de conflitos políticos". Nesta vertente, o autoconceito da sociedade industrial ainda predomina, seja multiplicando ou ainda "legitimando" as ameaças produzidas através de tomadas de decisão como "riscos residuais".

A outra fase é a que ocorre "quando os perigos da sociedade industrial começam a dominar os debates e conflitos públicos, tanto políticos como privados" (BECK, 1997, p. 15). As instituições da sociedade industrial tornam-se produtoras e legitimadoras das ameaças que não conseguem controlar.

Os argumentos anteriores demonstram que a avaliação de questões ligadas ao descarte de lixo tecnológico é importante para os estudos realizados no âmbito do campo Ciência, 
Tecnologia e Sociedade (CTS) dado que se vive em uma sociedade de risco. O relacionamento atual entre ciência, tecnologia e sociedade ocorre com permissividade quanto a eventuais riscos: os benefícios são superestimados e os riscos não revelados, ou minimizados, perante o público.

Neste contexto, esta pesquisa teve como objetivo geral mapear e analisar as redes sociais de produção e colaboração tecnológica em documentos de patentes, relativas às inovações sobre descarte de lixo tecnológico, também chamado de Resíduos de Equipamentos Elétricos e Eletrônicos (REEE).

Para isso, verificou-se:

a) os padrões de colaboração das redes de produção tecnológica identificadas, destacando as interações nos fluxos de conhecimento;

b) as redes formadas a partir da colaboração entre os inventores das patentes;

c) a origem institucional dos colaboradores identificados; $\mathrm{e}$,

d) as tendências tecnológicas das redes existentes sobre o descarte de REEE desenvolvidas em colaboração, compreendendo como o conhecimento tecnológico foi construído.

Este estudo teve caráter exploratório-descritivo e utilizou como principal ferramenta metodológica a Análise de Redes Sociais (ARS), caracterizada pelo mapeamento e mensuração dos fluxos e das relações presentes nas colaborações entre os inventores das patentes.

A pesquisa torna-se oportuna tendo em vista a importância de se analisar a colaboração tecnológica existente entre pesquisadores que trabalham com o tema dos resíduos sólidos urbanos, em especial os dos REEE, na qual a noção de sociedade de risco e de consumo, a que Beck (1997) se refere, se encaixa no tocante à sustentabilidade sócio-econômica-ambiental.

Além disso, tendo em vista a importância da temática aliada à originalidade da metodologia, nota-se que, no Brasil, a abordagem da análise de redes sociais de produção e colaboração tecnológica é pouco difundida quando comparada com a análise de redes de produção científica, e, desta maneira, poderá vir a ser consultada como referência quanto às possíveis parcerias existentes no ramo do descarte de REEE.

\section{Descarte de Resíduos de Equipamentos Elétricos e Eletrônicos}

A temática do lixo tecnológico está presente no dia a dia da população, pois "o uso crescente de equipamentos eletrônicos, tanto no sistema produtivo quanto nos bens de consumo, é fato inconteste, e sua reutilização ou reciclagem [no Brasil] é praticamente zero." (FERRAZ; BASSO, 2003, p. 288). Segundo os autores, seja pela falha de um componente ou pela morte programada pelo fabricante, o equipamento eletrônico inútil passa a ser valorizado por sua quantidade de materiais (plásticos, metais, vidro). Porém, o custo desse equipamento está em grande parte embutido na tecnologia de sua criação e não nos materiais utilizados. $\mathrm{O}$ equipamento defeituoso ou obsoleto passa a ter uma fração do valor que tinha, quando novo, sendo algo facilmente descartável.

A Diretiva do Parlamento Europeu (2003) - de 2002/96/EC - regula o descarte destes resíduos e define os EEE como os equipamentos cujo adequado funcionamento depende de correntes elétricas ou campos eletromagnéticos, bem como os equipamentos para geração, transferência e medição dessas correntes e campos concebidos para utilização com uma tensão nominal não superior a $1000 \mathrm{~V}$, para corrente alternada, e $1500 \mathrm{~V}$, para corrente contínua. Estabelece que os REEE são "os equipamentos elétricos ou eletrônicos que constituem resíduos, incluindo todos os componentes, subconjuntos e materiais que fazem parte do produto no momento em que este é descartado" (2003, p. 27).

Para entender o processo de descarte de um equipamento obsoleto ou que apresente características que suscitem o fim de sua vida útil, 
Manzini e Vezzoli (2008) esquematizam o ciclo de vida de um produto agrupando tais processos nas seguintes fases: pré-produção; produção; distribuição; uso; e, descarte. Neste sentido,

[...] no momento da 'eliminação' [descarte] do produto, abre-se uma série de opções sobre o seu destino final: pode-se recuperar a funcionalidade do produto ou de qualquer componente [reutilização]; pode-se valorizar as condições do material empregado ou o conteúdo energético do produto [reciclagem e/ou tratamento]; enfim, pode-se optar por não recuperar nada do produto [encaminhando-o diretamente para a disposição final]. (MANZINI; VEZZOLI, 2008, p. 96)

No primeiro caso, o produto - ou algumas de suas partes - podem ser reutilizados para a mesma função anterior ou para outra diferente. O produto destinado tanto à reutilização quanto à reciclagem deve ser separado dos resíduos comuns, coletado e transportado. Em alguns casos, o produto pode ser "refabricado" ou reprocessado, o que significa passar por transformações que permitem sua reutilização como se fosse novo. No final do processo, o que não é mais usado é destinado a ser despejado em lixos urbanos nem sempre legalizados - ou mesmo disperso no ambiente. No caso dos despejos em centros legais de processamento de lixo, os produtos eliminados devem ser devidamente recolhidos e transportados, bem como devem ser tratados aqueles que apresentarem substâncias tóxicas ou nocivas (MANZINI; VEZZOLI, 2008).

\section{Encaminhamento da investigação}

Este estudo teve caráter descritivo e exploratório e aplicou a metodologia de Análise de Redes Sociais (ARS), que permitiu o mapeamento e mensuração dos fluxos e das relações de colaboração tecnológica entre os inventores dos documentos de patentes recuperados na base de dados Espacenet, a qual tem acesso gratuito e está disponível online.

A ARS, realizada com o uso do software UCINET juntamente com o NetDraw, foi combinada ao monitoramento tecnológico de documentos de patentes, por meio da análise de patentes. $\mathrm{O}$ processo da investigação é detalhado a seguir.

\section{Análise de Patentes}

A análise de patentes é baseada no pressuposto de que o aumento do interesse por novas tecnologias se refletirá no aumento da atividade de Pesquisa e Desenvolvimento (P\&D) que, por sua vez, se verificará no aumento de depósito de patentes. Assim, presume-se que se podem identificar novas tecnologias pela análise dos padrões de pedidos de patentes em determinados campos. Os resultados são muitas vezes apresentados de forma quantificada, mas seu uso no processo decisório tem por base uma avaliação qualitativa (SANTOS et al., 2004).

Por isso, segundo Abraham e Moitra (2001, p. 246), "a análise de patentes tem sido considerada uma importante ferramenta para o acesso aos múltiplos aspectos de mudança tecnológica”. Muitos estudos utilizam estatísticas de patentes como método para compreender a relação entre desenvolvimento tecnológico e crescimento econômico, ou mesmo, o acesso à pesquisa e processos de inovação em um contexto nacional ou internacional.

No entanto, sabe-se que as invenções patenteadas não correspondem necessariamente a inovações, pois uma inovação de produto pode envolver várias patentes. Além disso, as invenções patenteadas geralmente não estão no formato "comercializável", sendo necessários desenvolvimentos (tecnológicos, organizacionais, de marketing, entre outros) para que se transformem em inovações de produto ou processo, ou seja, que se transformem em produtos/processos introduzidos no mercado (CARNEIRO et al., 2007).

Isto fica claro na definição de inovação do Manual de Oslo, que considera inovação a implementação de um produto novo ou significativamente melhorado (bem ou serviço) ou processo; um novo método de mercado - marketing; ou um novo método organizacional nas práticas de 
negócios, organização do local de trabalho ou relações externas para a empresa. Assim, um aspecto comum das inovações é que elas precisam ser implementadas (ORGANIZAÇÃO ..., 2004).

Neste sentido, Alves (2003) destaca que, como qualquer outro indicador tecnológico, a análise de patentes possui vantagens e desvantagens. Archibugi e Pianta (1996) destacam as seguintes vantagens no uso de patentes:

[e]vita a duplicação de esforços; auxilia o levantamento do estado da técnica; auxilia o estudo das trajetórias tecnológicas; encontra soluções para problemas técnicos; disponibiliza informações sobre oportunidades de licenciamento, de associação e de conhecimento de consumidores finais para certas tecnologias; identifica os concorrentes reais e potenciais e monitoram suas atividades; identifica os peritos e experts; demonstra o poderio das diversas empresas e suas estratégias de proteção dos direitos de suas patentes; assegura que os direitos patentários de terceiros não estejam sendo infringidos; garante o respeito aos direitos patentários de determinada empresa; identifica a maturidade e a importância da tecnologia; auxilia a formulação de políticas. (ARCHIBUGI; PIANTA, 1996, p. 452-453)

Os autores apresentam, igualmente, as seguintes desvantagens (limitações) quanto a este uso:

Nem toda invenção é tecnicamente patenteável: é o caso dos softwares, os quais são protegidos, legalmente, pela lei de direitos autorais (copyright); nem todas as invenções são patenteadas: algumas empresas protegem suas invenções através de métodos como o segredo industrial, em que a invenção é protegida sem a revelação de seus pormenores, deixando-a assim simplesmente desconhecida; as empresas possuem diferentes propensões (tendências, inclinações) a patentear, tanto no mercado interno como em outros países, impulsionada por suas expectativas de exploração comercial de suas invenções. (ARCHIBUGI; PIANTA, 1996, p. 453-454)

Segundo a Organização... (2004) tais limitações são controláveis. Para Schmookler (1962, p. 6) "temos a escolha de utilizarmos a análise de patentes continuamente e aprendermos com ela. Todo o progresso neste campo virá do uso racional desse indicador". Assim, a recuperação da informação por meio das bases de dados de patentes na web se torna uma fonte essencial de conhecimento.

\section{Universo de análise - seleção das palavras-chave}

No entender de Ferrari (1982, p. 139) “o universo, ou população, é o agregado de todos os elementos que possuem determinadas características, conforme definidas no próprio corpo de pesquisa".

Para a delimitação do universo a ser estudado, realizou-se um levantamento das fontes de informação formais a serem utilizadas: artigos científicos (de periódicos e de anais de eventos), relatórios técnicos, teses, dissertações, patentes, normas técnicas, leis e livros. As fontes de informação informais (representadas pelos especialistas) não foram selecionadas para $o$ estudo do universo.

Para a recuperação e coleta das fontes de informação supracitadas, utilizaram-se as seguintes bases de dados: Google; Google Acadêmico; SciELO; Web of Science; Scopus; Compendex; JusBrasil; Diário Oficial; Derwent Innovations Index e Espacenet.

Considerou-se - para a seleção e extração de possíveis termos de busca que utilizados - apenas a literatura como fonte principal de informação e indicada pelos seguintes autores: Lindhqvist (2000); Ferraz e Basso (2003); Spengler, Ploog e Schröter (2003); Ciuccio (2004); Hilty (2005); Puckett e Smith ([2001]); Cooper (2005); Widmer et al. (2005); Schwarzer et at. (2005); Besen (2006); Logarezzi (2006); Rodrigues (2007); Seki (2007); Ansanelli (2008); Ferreira e Ferreira (2008); Azevêdo, Irizawa Filho e Galão (2008); Stowe (2008); Dias e Moraes Filho (2008); Mattos, Mattos e Perales (2008); Noronha (2008); Carroll (2008); Ribeiro e Morelli (2009); Vieira, Soares e Soares (2009); Waldman (2010); Ansanelli (2011); NBR 10.004 (Associação Brasileira de Normas Técnicas, 2004); e, Lei n. 6.938 (de 31 de agosto de 1981) que institui a Política Nacional de Meio Ambiente (PNMA) (Brasil, 1981). 
No total, foram selecionados 37 (trinta e sete) termos/palavras-chave, das quais 17 (dezessete) estão no idioma português (brasileiro) e 20 (vinte) no idioma inglês (Quadro 1).

A partir do levantamento das palavras-chave a serem utilizadas no monitoramento tecnológico (e posterior confecção das redes de colaboração), realizou-se um estudo das principais bases de dados de patentes, como descrito a seguir.

Quadro 1 - Palavras-chave selecionadas para o universo de análise

\begin{tabular}{|c|c|}
\hline 1. & $\begin{array}{l}\text { "descarte de equipamentos e componentes } \\
\text { eletronicos e tecnologicos" }\end{array}$ \\
\hline 2. & "lixo digital" \\
\hline 3. & "digital garbage" \\
\hline 4. & "lixo high tech" \\
\hline 5. & "high tech trash" \\
\hline 6. & "descarte de aparatos e dispositivos tecnicos" \\
\hline 7. & "disposal of apparatus and technical devices" \\
\hline 8. & "descarte de lixo tecnologico" \\
\hline 9. & $\begin{array}{l}\text { "disposal of equipment and electronic components } \\
\text { and technological" }\end{array}$ \\
\hline 10. & "electronic scrap" \\
\hline 11. & "electronic scrap recovery" \\
\hline 12. & $\begin{array}{l}\text { "electronical and electronic products post- } \\
\text { consumer" }\end{array}$ \\
\hline 13. & "electrical and electronic waste" \\
\hline 14. & "electric-electronic garbage" \\
\hline 15. & "electronic waste" \\
\hline 16. & "e-lixo" \\
\hline 17. & "e-scrap" \\
\hline 18. & "e-waste" \\
\hline 19. & "lixo eletrico-eletronico" \\
\hline 20. & "lixo eletronico" \\
\hline 21. & "lixo tecnologico" \\
\hline 22. & "post-consumer waste" \\
\hline 23. & "produtos eletricos e eletronicos pos-consumo" \\
\hline 24. & "reciclagem de lixo tecnologico" \\
\hline 25. & "recuperacao de sucata eletronica" \\
\hline 26. & "residuos de equipamentos eletricos e eletronicos" \\
\hline 27. & "residuos de tecnologia da informacao" \\
\hline 28. & "residuos pos-consumo" \\
\hline 29. & "residuos tecnologicos" \\
\hline 30. & "sucata eletronica" \\
\hline 31. & "tech trash" \\
\hline 32. & "technological waste" \\
\hline 33. & "waste disposal technology" \\
\hline 34. & "waste electrical and electronic equipment" \\
\hline 35. & "waste electrical-electronic" \\
\hline 36. & "waste of information technology" \\
\hline 37. & "waste recycling technology" \\
\hline
\end{tabular}

Fonte: os autores.
Universo de análise - seleção da base de dados

Para a delimitação do universo a ser estudado, foi realizado um levantamento das principais bases de dados de patentes e realizado um pré-teste com os termos de busca, previamente retirados da literatura, a fim de se comparar, entre as bases de dados, os seguintes aspectos: a facilidade dos mecanismos de busca; a interface; e o retorno de cada base por palavra-chave.

As bases de dados selecionadas para este pré-teste de exploração foram:

\section{Bases gratuitas:}

a) Espacenet: base de dados do escritório europeu de patentes. Oferece pesquisa rápida, avançada, por número, por classificação europeia (ECLA) e por classificação internacional de patentes (IPC). Abrange pedidos depositados a partir de 1836, com atualização semanal;

b) Google Patents: base de dados americana usada como alternativa à USPTO. Oferece busca simples e avançada que cobre todo o conteúdo do documento de patente e não apenas o título ou resumo. Salva os documentos em formato portable document format (pdf);

c) INPI: base de dados do Instituto Nacional da Propriedade Industrial. Disponibiliza pesquisa básica e avançada abrangendo os pedidos depositados a partir de 1992. Atualização semanal;

d) IPDL (Industrial Property Digital Library): base de dados do escritório japonês de patentes (Japan Patent Office). Oferece pesquisa básica, por número de patente, por depositante e por classificação internacional de patentes (IPC). Abrange o período a partir do ano de 1976, sendo atualizada semanalmente;

e) PatentScope: base de dados de patentes da Organização Mundial da Propriedade 
Intlectual (World Intellectual Property Organization). Disponibiliza busca simples para recuperação dos dados na primeira página do documento, em qualquer campo, no texto integral, por número ID, por classificação internacional de patentes (IPC), por nomes e por datas. Abrange pedidos de 24 países, somados aos pedidos Patent Cooperation Treaty (PCT) e base EPO. Cobertura desde 1930;

f) USPTO (United States Patent and Trademark Office): base do escritório americano de patentes. Oferece pesquisa rápida, avançada e por número. Abrange pedidos de patentes desde 1790. Tem atualização semanal.

\section{Bases proprietárias (pagas):}

g) Derwent Innovations Index: base de dados de patentes internacionais e um índice de citações de patentes. Oferece pesquisa geral (simples), avançada e por patente citada. Abrange os pedidos de patentes a partir de 1963, com atualização semanal de 20 mil registros.

A Tabela 1 apresenta a quantificação do pré-teste realizado nas bases de dados mencionadas, que teve como objetivo a seleção daquela que melhor representa a área estudada.

Para compilação do universo desta pesquisa foi utilizada a base de dados de patentes Espacenet, cuja representatividade se conforma pelos seguintes critérios (ESPACENET, 2011):

a) é online, gratuita e multidisciplinar (patentes de diversas áreas do conhecimento);

b) abrange as patentes depositadas na base de dados do escritório brasileiro de patentes - o Instituto Nacional da Propriedade Industrial (INPI) - e de outros 85 países;

c) contém patentes publicadas a partir do ano de 1836 até o presente;

d) interface amigável e de fácil uso; e e) utiliza diversos mecanismos de busca (simples/rápida, avançada, por número, pela ECLA, e pela IPC).

$\mathrm{Na}$ aplicação dos procedimentos de coleta de dados na base Espacenet definiu-se:

a) que os 37 (trinta e sete) termos utilizados como sinônimo sobre novas tecnologias em descarte de lixo tecnológico (QUADRO 1) deveriam ser utilizados entre aspas, visando a recuperação da expressão exata; e restritos somente aos campos título e resumo; e

b) que os termos em português fossem utilizados sem a devida acentuação. Devido aos mecanismos de indexação da base, o uso de acentuação e outros sinais gráficos próprios do idioma poderiam ocasionar sucessivos erros de sintaxe.

\section{A Análise de Redes Sociais enquanto instrumento metodológico}

Cross, Parker e Borgatti (2000) consideram a ARS um importante instrumento para entender relacionamentos que alimentam o compartilhamento da informação e do conhecimento. Trata-se, portanto, de uma metodologia que permite a identificação de indicadores de padrões de relacionamentos, permitindo um entendimento das colaborações existentes entre os atores (nós) pertencentes a uma rede.

A aplicação da ARS, embora seja comumente utilizada no entendimento dos relacionamentos dentro das organizações, vem sendo aplicada no mapeamento das colaborações científicas e mais recentemente no mapeamento das colaborações tecnológicas.

Neste sentido, foram mapeadas as colaborações com base em informações tecnológicas com o intuito de explorar as parcerias tecnológicas existentes no universo de documentos de 
Tabela 1 - Comparação dos pré-testes realizados nas bases de dados de patentes

\begin{tabular}{|c|c|c|c|c|c|c|c|}
\hline \multirow[t]{2}{*}{ TERMOS } & \multicolumn{7}{|c|}{$\begin{array}{c}\text { NÚMERO DE REGISTROS DE PEDIDOS DE PATENTES } \\
\text { RECUPERADOS POR BASE DE DADOS }\end{array}$} \\
\hline & Espacenet & $\begin{array}{l}\text { Google } \\
\text { Patents }\end{array}$ & INPI & JPO & PATENTSCOPE & USPTO & DII \\
\hline TOTAL & 170 & 1673 & 30 & 133005 & 776 & 333 & 361 \\
\hline "digital garbage" & 0 & 1 & 0 & 15 & 1 & 0 & 0 \\
\hline $\begin{array}{l}\text { "disposal of apparatus and } \\
\text { technical devices" }\end{array}$ & 0 & 0 & 0 & 10 & 0 & 0 & 0 \\
\hline $\begin{array}{l}\text { "disposal of equipment and } \\
\text { electronic components and } \\
\text { technological" }\end{array}$ & 0 & 0 & 0 & 3 & 0 & 0 & 0 \\
\hline $\begin{array}{l}\text { "electrical and electronic } \\
\text { waste" }\end{array}$ & 0 & 3 & 0 & 365 & 3 & 1 & 2 \\
\hline "electronic scrap recovery" & 0 & 0 & 0 & 3 & 0 & 0 & 1 \\
\hline "electronic scrap" & 55 & 200 & 0 & 108 & 67 & 67 & 98 \\
\hline "electronic waste" & 79 & 288 & 0 & 1434 & 84 & 51 & 108 \\
\hline "e-lixo" & 0 & 0 & 0 & 1 & 90 & 0 & 0 \\
\hline "e-scrap" & 0 & 29 & 0 & 8239 & 4 & 0 & 1 \\
\hline "e-waste" & 0 & 6 & 0 & 120917 & 129 & 2 & 27 \\
\hline "lixo eletrico-eletronico" & 0 & 0 & 1 & 0 & 0 & 0 & 0 \\
\hline "lixo eletronico" & 0 & 0 & 2 & 0 & 2 & 0 & 0 \\
\hline "lixo tecnologico" & 0 & 0 & 10 & 0 & 0 & 0 & 0 \\
\hline "post-consumer waste" & 0 & 963 & 0 & 1 & 292 & 147 & 65 \\
\hline $\begin{array}{l}\text { "reciclagem de lixo } \\
\text { tecnologico" }\end{array}$ & 0 & 0 & 3 & 0 & 0 & 0 & 0 \\
\hline "residuos pos-consumo" & 0 & 0 & 12 & 0 & 0 & 0 & 0 \\
\hline "residuos tecnologicos" & 0 & 0 & 2 & 0 & 0 & 0 & 0 \\
\hline "tech trash" & 0 & 0 & 0 & 1 & 0 & 0 & 0 \\
\hline "technological waste" & 30 & 32 & 0 & 1456 & 13 & 15 & 40 \\
\hline "waste disposal technology" & 1 & 15 & 0 & 161 & 7 & 16 & 4 \\
\hline $\begin{array}{l}\text { "waste electrical and } \\
\text { electronic equipment" }\end{array}$ & 1 & 133 & 0 & 73 & 83 & 32 & 14 \\
\hline "waste electrical-electronic" & 0 & 1 & 0 & 1 & 1 & 0 & 0 \\
\hline $\begin{array}{l}\text { "waste of information } \\
\text { technology" }\end{array}$ & 0 & 0 & 0 & 71 & 0 & 0 & 0 \\
\hline "waste recycling technology" & 4 & 2 & 0 & 146 & 0 & 2 & 1 \\
\hline
\end{tabular}

Fonte: os autores.

patentes recuperado sobre REEE na base de principaldecolaboraçãotecnológica, apresentado dados Espacenet. na Figura 1.

\section{Resultados e Conclusões}

A partir de exploração dos dados recuperados na base de dados Espacenet obteve-se o mapa
A análise dos resultados permitiu verificar que todas as colaborações tecnológicas são entre inventores do mesmo país, ou seja, a rede de coinventores é fracamente conectada, demonstrando a inexistência de ligações individuais entre atores de diferentes clusters $^{1}$. Isto

\footnotetext{
1 "Clusters são grupos que se formam a partir de nós muito conectados. Em termos de redes sociais, os clusters são considerados grupos sociais coesos. Podem ser unidos a outros grupos através de laços individuais de seus membros" (RECUERO, 2005, p. 4).
} 
Figura 1 - Mapa de colaboração tecnológica sobre REEE

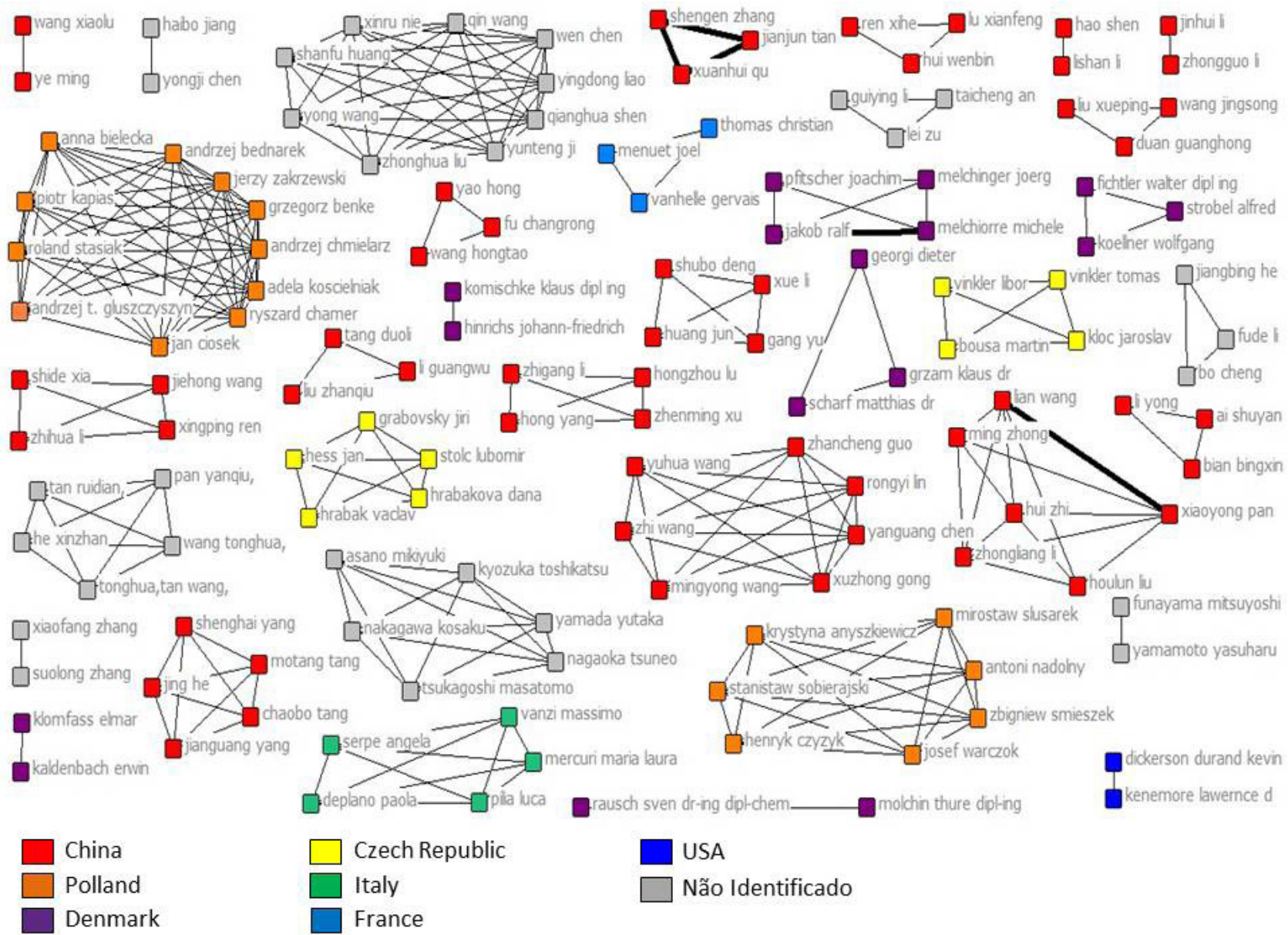

Fonte: os autores.

remete a pouca expressividade da colaboração internacional neste campo de interesse.

Dentre os países analisados, a China é o país com maior número de colaborações (endógenas) e de depósitos de patentes sobre os REEE. Este dado sinaliza uma liderança deste país neste campo. Também chama a atenção a presença de redes significativas de pesquisadores de origem polonesa. Tendo em vista o caráter periférico deste país na produção de tecnologia de ponta, sugere-se, a título de agenda de pesquisa, uma investigação qualitativa das possíveis razões para sua presença expressiva neste campo.

As razões para a o caráter internalizado da colaboração tecnológica nesta área podem estar ligadas às seguintes hipóteses: a) as dificuldades inerentes à colaboração tecnológica transnacional, por conta das distâncias geográficas, custos de deslocamentos, barreiras linguísticas etc. Estas limitações são ainda mais expressivas em áreas de $\mathrm{P} \& \mathrm{D}$ tecnológico, as quais requerem experimentações, laboratórios e uso de equipamentos dedicados; e

b) a inexistência de harmonização legal para regulação da propriedade industrial, inclusive patentes, no plano internacional. Isto significa que são elevados os custos de transação (financeiros, jurídicos, etc.) para registro da propriedade industrial da invenção que é fruto de colaboração internacional, uma vez que deverá ser depositado um pedido de patente no país de origem de cada inventor. 
Neste sentido observa-se que a ausência de harmonização legal no campo da propriedade industrial constitui um forte obstáculo para a colaboração internacional na produção tecnológica relacionada ao descarte de REEE, visto que não proporciona segurança jurídica para os inventores.

\section{Referências}

ABRAHAM, B. P.; MOITRA, S. D. Innovation assessment through patent analysis. Technovation, v. 21, n. 4, p. 245-252, abr. 2001. Disponível em: <http://dx.doi. org/10.1016/S0166-4972(00)00040-7>. Acesso em: 23 out. 2012.

ABRAMOVAY, R. Entre Deus e o diabo: mercados e interação humana nas ciências sociais. Tempo Social: Revista de Sociologia da USP, v. 16, n. 2, p. 35-64. 2004. Disponível em: <http://dx.doi.org/10.1590/S0103$20702004000200002>$. Acesso em: 23 out. 2012.

ALVES, J. M. S. Análise de patentes na indústria avícola internacional. Dissertação (Mestrado) - Universidade Federal do Rio Grande do Sul, Porto Alegre, 2003.

ANSANELLI, S. L. M. Exigências ambientais europeias: novos desafios competitivos para o complexo eletrônico brasileiro. Revista Brasileira de Inovação, v. 10, n. 1, p.129-160, jan./jun. 2011. Disponível em: <http://www.ige.unicamp.br/ojs/index.php/rbi/article/ view/552/301>. Acesso em: 23 out. 2012.

ANSANELLI, S. L. M. Os impactos das exigências ambientais europeias para equipamentos eletroeletrônicos sobre o Brasil. 227 f. Tese (Doutorado em Economia)- Universidade Estadual de Campinas, Campinas, 2008.

ARCHIBUGI, D.; PIANTA, M. Measuring technological change through patents and innovation surveys. Technovation, v. 16, n. 9, p. 451-468. 1996. Disponível em: <http://dx.doi.org/10.1016/0166-4972(96)000314>. Acesso em: 23 out. 2012.

ASSOCIAÇÃO BRASILEIRA DE NORMAS TÉCNICAS. NBR 10.004: resíduos sólidos - classificação. Rio de Janeiro, 2004. 71 p.

AZEVÊDO, A. C.; IRIZAWA FILHO, E. K.-I.; GALÃO, F. P. Percepções do consumidor sobre o meio ambiente e o lixo eletrônico em empresas de informática: um estudo exploratório na cidade de Londrina. In: CONGRESSO INTERNACIONAL DE ADMINISTRAÇÃO, Ponta Grossa, 2008. Anais... Ponta Grossa, 2008.
BAUMAN, Z. Os consumidores na sociedade líquidomoderna. In: Vida líquida. Rio de Janeiro: Zahar, 2007. p. 106-151.

BECK, U. A reinvenção da política: rumo a uma teoria da modernização reflexiva. In: BECK, U.; GIDDENS, A.; LASH, S. Modernização reflexiva: política, tradição e estética na ordem social moderna. São Paulo: EdUNESP, 1997. p. 11-71.

BESEN, G. R. Programas municipais de coleta seletiva em parceria com organizações de catadores na Região Metropolitana de São Paulo: desafios e perspectivas. 2006. 207 f. Dissertação (Mestrado em Saúde Pública) - Faculdade de Saúde Pública da Universidade de São Paulo, São Paulo, 2006.

BRASIL. Lei n. 6.938, de 31 de agosto de 1981. Dispõe sobre a Política Nacional do Meio Ambiente, seus fins e mecanismos de formulação e aplicação, e dá outras providências. Diário Oficial [da] República Federativa do Brasil, Poder Executivo, Brasília, DF. Disponível em: <http://www.mma.gov.br/estruturas/ revizee/_legislacao/19_legislacao18122008091210. pdf>. Acesso em: 18 out. 2012.

CARNEIRO, A. M.; BONACELLI, M. B.; CONDER, S.; ZACKIEWICZ, M.; REZENDE, A. S. de.; TAME, P. Monitoramento tecnológico: desafios para ir além do P\&D. In: Seminário Latino-Iberoamericano de Gestion Tecnológica - ALTEC, 12. Buenos Aires: Secretaria de Ciencia, Tecnología e Innovación Productiva, 2007, p. 1-16.

CARROLL, C. High-tech trash: will your discarded TV end up in a ditch in Ghana? National Geographic Magazine. Jan. 2008. Disponível em: <http://ngm. nationalgeographic.com/2008/01/high-tech-trash/ carroll-text>. Acesso em: 18 out. 2012.

CIUCCIO, M. T. P. Estudo de tendências e oportunidades no desenvolvimento sustentável para a reciclagem de veículos e seus materiais. $211 \mathrm{f}$. Dissertação (Mestrado em Engenharia de Materiais)Universidade Federal de São Carlos, São Carlos, 2004.

COOPER, T. Slower consumption: reflections on product life spans and the "throwaway society". Journal of Industrial Ecology, v. 9, n. 1-2, p. 51-67, 2005. Disponível em: <http://dx.doi.org/ 10.1162/1088198054084671>. Acesso em: 23 out. 2012.

COSTA, J. F. O vestígio e a aura: corpo e consumismo na moral do espetáculo. Rio de Janeiro: Garamond, 2004.

CROSS, R.; PARKER, A.; BORGATTI, S. P. A bird'seye view: using social network analysis to improve knowledge creation and sharing. Knowledge 
Directions, v. 2, n. 1, p. 48-61, 2000. Disponível em: $<$ http://www.gslis.utexas.edu/ i385q/spring2005/ readings/Cross_2002_using_social_network.pdf>. Acesso em: 23 out. 2012.

DIAS, J. A.; MORAES FILHO, A. M. Os resíduos sólidos e a responsabilidade ambiental pós-consumo. 2. ed. rev. atual. [s.l.], 2008. 100 p. Disponível em: <http:// www.prsp.mpf.gov.br/prmmarilia/sala-de-imprensa/ livro_pos_consumo_2ed.pdf>. Acesso em: 18 out. 2012.

\section{DIRETIVA DO PARLAMENTO EUROPEU E DO} CONSELHO, de 27 de janeiro de 2003, relativa aos resíduos de equipamentos elétricos e eletrônicos (REEE). Jornal Oficial da União Europeia, v. 37, p. 24-38. Disponível em: <http://www.aipi.pt/files/1753 Directiva_2002-96-CE_\%28REEE\%29_\%28Portugues \%29_43d4e5ed9c191.pdf>. Acesso em: 18 out. 2012.

ESPACENET. Página inicial. Disponível em: <http:// lp.espacenet.com/>. Acesso em: 18 out. 2012.

FERRARI, A. T. Metodologia da pesquisa científica. São Paulo: McGraw-Hill, 1982.

FERRAZ, M. C. C.; BASSO, H. C. Resíduos sólidos formados por lixo eletrônico: riscos ambientais e política de reaproveitamento. In: FÓRUM DAS UNIVERSIDADES PÚBLICAS PAULISTAS: CIÊNCIA E TECNOLOGIA EM RESÍDUOS, 1., 2003, São Pedro. Anais... São Pedro: Instituto de Ciência e Tecnologia em Resíduos e Desenvolvimento Sustentável, 2003. p. 286-296.

FERREIRA, J. M. B.; FERREIRA, A. C. A sociedade da informação e o desafio da sucata eletrônica. Revista de Ciências Exatas e Tecnologia, Valinhos, v. 3, n. 3, p. 157-170, 2008. Disponível em: <http://sare. unianhanguera.edu.br/index.php/rcext/article/ view/417/413>. Acesso em: 23 out. 2012.

HARVEY, D. Do fordismo à acumulação flexível. In: . A condição pós-moderna. São Paulo: Loyola, 1993. p. 135-162.

HILTY, L. M. Electronic waste: an emerging risk? Environmental Impact Assessment Review, v. 25, p. 431-435, 2005. Disponível em: <http://dx.doi.org/ 10.1016/j.eiar.2005.04.002>. Acesso em: 23 out. 2012.

\section{LINDHQVIST, T. Extended producer responsibility} in cleaner production: policy principle to promote environmental improvements of products systems. 2000. 196 f. Tese (Doutorado) - Lund University, Sweden, 2000.
LOGAREZZI, A. Educação ambiental em resíduo: uma proposta de terminologia. In: CINQUETTI, H. C. S. (Org.); LOGAREZZI, A. (Org.). Consumo e resíduo: fundamentos para o trabalho educativo. São Carlos: EdUFSCar, 2006. p. 85-117.

\section{MANZINI, E.; VEZZOLI, C. O desenvolvimento de} produtos sustentáveis: os requisitos ambientais dos produtos industriais. Astrid de Carvalho (Trad.). São Paulo: EdUSP, 2008.

MATTOS, K. M. C.; MATTOS, K. M. C.; PERALES, W. J. S. Os impactos ambientais causados pelo lixo eletrônico e o uso da logística reversa para minimizar os efeitos causados ao meio ambiente. In: ENCONTRO NACIONAL DE ENGENHARIA DE PRODUÇÃO, 28., Rio de Janeiro, 2008. Anais... Rio de Janeiro, 2008.

NORONHA, G. V. G. A opulência planejada e a dúvida do destino do lixo. $100 \mathrm{f}$. Dissertação (Mestrado em Políticas Sociais e Cidadania)- Universidade Católica de Salvador, Salvador, 2008.

\section{ORGANIZAÇÃO PARA COOPERAÇÃO E} DESENVOLVIMENTO ECONÔMICO. Manual de Oslo: proposta de diretrizes para coleta e interpretação de dados sobre inovação tecnológica: mensuração das atividades científicas. [S.l.]: OCDE, FINEP, 2004.

PUCKETT, J.; SMITH, D. Poison PCs and toxic TVs. [Junho, 2001]. Disponível em: <http://svtc.org/wpcontent/uploads/ppc-ttv1.pdf> . Acesso em: 18 out. 2012.

RAUD-MATTEDI, C. A construção social do mercado em Durkheim e Weber: análise do papel das instituições na sociologia econômica clássica. Revista Brasileira de Ciências Sociais, v. 20, n. 57, p. 127-142. 2005. Disponível em: <http://dx.doi.org/10.1590/S0102$69092005000100008>$. Acesso em: 23 out. 2012.

RECUERO, R. C. Redes sociais na internet: considerações iniciais. Revista E-Compoós, abr. 2005. Disponível em: <http://www.compos.org.br/seer/index.php/e-compos/ article/view/28/29>. Acesso em: 23 out. 2012.

RIBEIRO, D. V.; MORELLI, M. R. Resíduos sólidos: problema ou oportunidade? Rio de Janeiro: Interciência, 2009.

RODRIGUES, A. C. Impactos sócio-ambientais dos resíduos de equipamentos elétricos e eletrônicos: estudo da cadeia pós-consumo no Brasil. 2007. $321 \mathrm{f}$. Dissertação (Mestrado em Engenharia de Produção)Universidade Metodista de Piracicaba, Santa Bárbara D’Oeste, 2007. 
SANTOS, M. M.; COELHO, G. M.; SANTOS, D. M. dos.; FELLOWS FILHO, L. Prospecção de tecnologias de futuro: métodos, técnicas e abordagens. Parcerias Estratégicas, n. 19, p. 189-229, dez. 2004. Disponível em: <http://seer.cgee.org.br/index.php/parcerias_ estrategicas/article/viewFile/253/247>. Acesso em: 23 out. 2012.

SCHMOOKLER, J. Economic sources of inventive activity. Journal of Economic History, v. 22, n. 1, p. 1-20, Mar. 1962. Disponível em: <http://www.jstor.org/ stable/2114253>. Acesso em: 23 out. 2012.

SCHWARZER, S. et al. E-waste: the hidden side of IT equipment's manufacturing and use. Environment Alert Bulletin - United Nations Environment Programme, jan. 2005.

SEKI, T. T. Gerenciamento de resíduos de equipamentos elétricos e eletrônicos na Universidade Federal de São Carlos e no programa de coleta seletiva do município de São Carlos. $112 \mathrm{f}$. Monografia (Bacharelado em Física)- Universidade Federal de São Carlos, São Carlos, 2007.

SPENGLER, T.; PLOOG, M.; SCHRÖTER, M. Integrated planning of acquisition, disassembly and bulk recycling: a case study on electronic scrap recovery. OR Spectrum, v. 25, p. 413-442, 2003. Disponível em: <http://dx.doi.org/10.1007/s00291-003-0119-5>. Acesso em: 23 out. 2012.

STOWE, D. Electronic scrap: political pressures and regulatory challenges. E-Scrap Marketplace, 2008. Disponível em: <http://www.tauber.umich.edu/ David\%20Stowe/4_Electronic\%20Scrap-\%20\%20 Political\%20Pressures\%20and\%20Regulatory\%20 Challenges.pdf>. Acesso em: 18 out. 2012.

VIEIRA, K. N.; SOARES, T. O. R.; SOARES, L. R. A logística reversa do lixo tecnológico: um estudo sobre o projeto de coleta de lâmpadas, pilhas e baterias da BRASKEM. Revista de Gestão Social e Ambiental, v. 3, n. 3, p. 120-136, set./dez. 2009. Disponível em: $<$ http://dx.doi.org/10.5773/rgsa.v3i3.180>. Acesso em: 23 out. 2012.

WALDMAN, M. Lixo: cenários e desafios: abordagens básicas para entender os resíduos sólidos. São Paulo: Cortez, 2010.

WIDMER, R. et al. Global perspectives on e-waste.

Environmental Impact Assessment Review, v. 25, p. 436-458, 2005. Disponível em: <http://dx.doi. org/10.1016/j.eiar.2005.04.001>. Acesso em: 23 out. 2012 .
Social networks of technological production and cooperation related to the disposal of electrical and electronic waste

\section{Abstract}

Introduction: This research aimed to map and analyze social networks of production and technology collaboration in patent documents related to innovations in waste disposal technology, also called the Electrical and Electronic Equipment Waste. The theoretical framework is relevant to the field of study "Science, Technology and Society". Method: The methodology was based on the application of techniques on the Social Network Analysis, characterized by mapping and measuring relationships and flows and collaborations among inventors of patents for innovations related to waste disposal technology. Results: The results show little expression of international collaboration. Regarding to the registration of patents on disposal of Electrical and Electronic Equipment Waste the leadership in this field appears to belong to China. Conclusions: The possible causes of low international collaboration in this area of technological research come from a lack of legal harmonization in the field of industrial property, associated with geographical distance, language barriers and high costs incurred in transnational technology collaboration.

\section{Keywords}

Technological waste. Collaboration in social networks. Patents. Technological research. Technological production. Technological innovation.

\section{Agradecimentos:}

As autoras agradecem à Coordenação de Aperfeiçoamento de Nivel Superior (CAPES) e à Fundação de Amparo à Pesquisa do Estado de São Paulo (FAPESP) pelo financiamento.

Recebido em 10 de setembro de 2012

Aceito em 10 de outubro de 2012 
Sobre as autoras:

\section{Luciara Cid Gigante}

Bacharel em Biblioteconomia e Ciência da Informação Universidade Federal de São Carlos (UFSCar), Mestre em Ciência, Tecnologia e Sociedade - Universidade Federal de São Carlos (UFSCar), Doutoranda em Política Científica e Tecnológica - Universidade Estadual de Campinas (UNICAMP).

luciaragigante@yahoo.com.br

\section{Camila Carneiro Dias Rigolin}

Bacharel em Administração - Universidade Federal da Bahia (UFBA), Mestre em Administração - Universidade Federal da Bahia (UFBA), Doutora em Política Científica e Tecnológica - Universidade Estadual de Campinas (UNICAMP). Estágio Pós-Doutoral em Estudos Sociais de Ciência e Tecnologia - Universidade Federal de São Carlos (UFSCar). Professora Adjunta do Departamento de Ciência da Informação e do Programa de Pós-Graduação em Ciência, Tecnologia e Sociedade - Universidade Federal de São Carlos (UFSCar). diasrigolin@ufscar.br

\section{Júlia Fernandes Marcelo}

Bacharel em Biblioteconomia e Ciência da Informação e Mestre em Ciência, Tecnologia e Sociedade - Universidade Federal de São Carlos (UFSCar).

juliaohana@hotmail.com

Como citar este artigo:

GIGANTE, L. C.; RIGOLIN, C. C. D.; MARCELO, J. F. Redes sociais de produção e colaboração tecnológica para o descarte de resíduos de equipamentos elétricos e eletrônicos. AtoZ, Curitiba, v. 1, n. 2, p. 11-22, jan./dez. 2012. Disponivel em: $<h t t p: / / w w w . a t o z . u f p r . b r>$. Acesso em: 